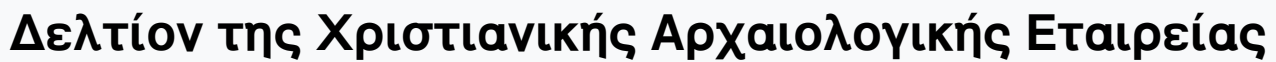

Tóp. 19 (1997)

$\Delta \varepsilon \lambda$ tíov XAE 19 (1996-1997), Пврі́обос $\Delta^{\prime}$

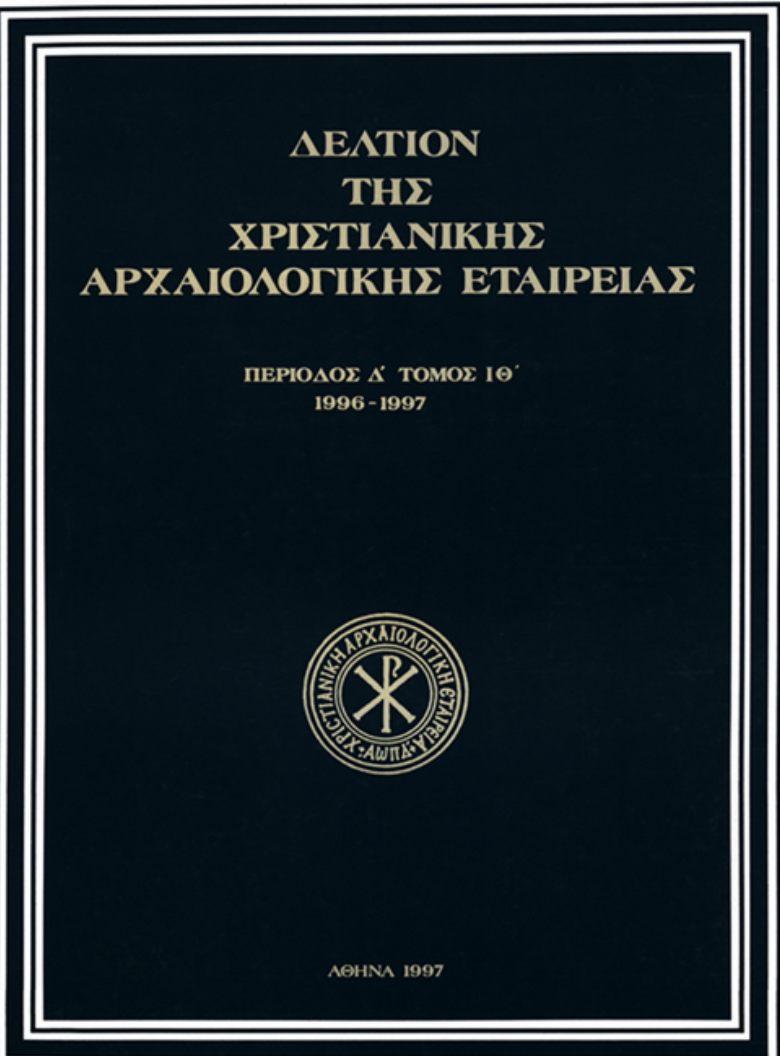

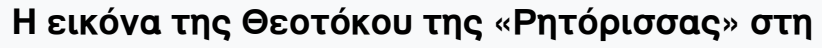

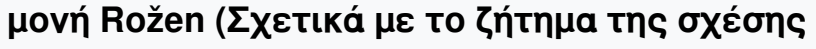

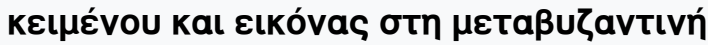

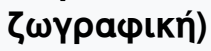

Bisserka PENKOVA

doi: $10.12681 /$ dchae. 1166

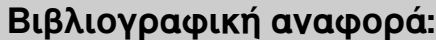

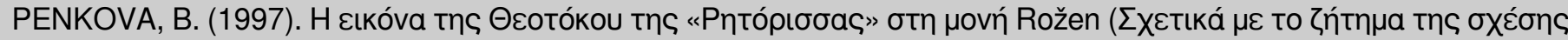

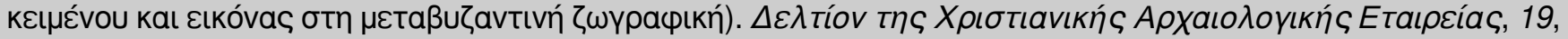
117-124. https://doi.org/10.12681/dchae.1166 


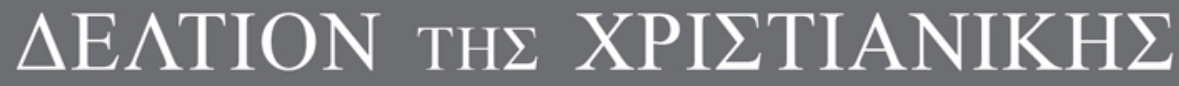 APXAIO $\Lambda$ OГIKH $\Sigma$ ETAIPEIA $\Sigma$}

Die Ikone der Gottesmutter Rhetorissa im Kloster Rožen (Zum Problem des Verhältnisses von Text und Bild in der Postbyzantinischen Malerei

Bisserka PENKOVA

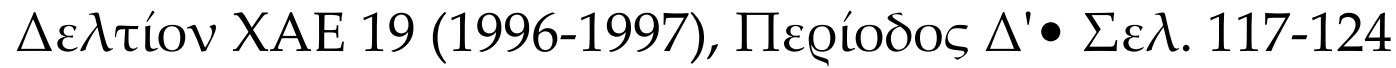
A@HNA 1997 


\section{Bisserka Penkova}

\section{DIE IKONE DER GOTTESMUTTER RHETORISSA IM KLOSTER ROŽEN (ZUM PROBLEM DES VERHÄLTNISSES VON TEXT UND BILD IN DER POSTBYZANTINISCHEN MALEREI)*}

$\mathrm{D}$ ie postbyzantinische Malerei auf dem Balkan ist ein besonderes künstlerisches Phänomen, das auf eine unübertroffene Art und Weise die jahrhundertealte byzantinische Tradition mit einer Reihe neuer künstlerischer Ideen sowohl aus dem Westen als auch aus dem Osten vereint. Sie liefert hinsichtlich ihrer Ikonographie des öfteren einmalige Beispiele für ihre Besonderheit. Diese Beispiele legen nahe, an jedes einzelne Denkmal mit besonderer Aufmerksamkeit heranzugehen. Dabei ist besonders das soziale und geistige Leben auf dem Balkan nach der Zerstörung von Byzanz und der anderen christlichen Staaten des Balkans und sowie nach der Gründung des Osmanischen Reiches zu berücksichtigen. Im Balkanraum läßt sich in diesem Zeitraum eine spezifische «postbyzantinische» Ikonographie feststellen, die zwar in der byzantinischen Tradition verwurzelt war, gleichzeitig aber auch zahlreiche unterschiedliche Einflüsse aufgenommen und eigene originelle Formen entwickelt hat. Im Vergleich zur vorangegangenen byzantinischen Zeit waren die künstlerischen Prozesse in der Zeit der osmanischen Fremdherrschaft auf dem Balkan von einer ganz neuen künstlerischen Qualität. So erweist sich das methodologische Instrumentarium der klassischen Ikonographie öfters als unzureichend für die Interpretation einer Reihe von Denkmälern der postbyzantinischen Kunst. Dem Problem der sogenannten westlichen Einflüsse auf die postbyzantinische Malerei, die sich in erster Linie durch die Werke der berühmten kretischen Malerschule durchsetzten, hat sich die Forschung seit längerem angenommen. Die Einflüsse aus dem Osten, besonders aus der Blütezeit der russischen Kunst des 16. und 17. Jahrhunderts, sind jedoch noch nicht angemessen untersucht worden vielleicht deshalb, weil sie

\footnotetext{
* Eine erste Fassung dieses Textes wurde auf der Konferenz «Zypern und Rußland im 17. Jh.» im Oktober 1995 in Moskau gehalten. Während meines Forschungsaufenthalts im Jahre 1996 am Seminar für Byzantinistik in Münster als A. von Humboldt-Stipendiatin wurde
}

schwächer ausgeprägt waren als die westlichen. Die Ikone im Kloster «Geburt der Gottesmutter», auch RoženKloster genannt, liefert ein Beispiel für die typische Entfaltung künstlerischer Ideen der postbyzantinischen Zeit des Balkans und soll aus diesem Grund näher beleuchtet werden.

Das Kloster von Rožen ist das wichtigste und älteste Kloster im Piringebiet. Es liegt am Fuße des Piringebirges, ca. fünf $\mathrm{Km}$ nordöstlich von der alten Stadt Melnik entfernt. Es wird angenommen, daß es im 13.-14. Jh. entstanden ist, doch liegen keine direkten Angaben über seine früheste Geschichte vor. Die bis heute erhaltenen Klosterbauten zeugen von dem Aufblühen des Klosters im 16. Jh. In der zweiten Jahrhunderthälfte wurden die Hauptkirche des Klosters sowie sein Refektorium erbaut und bemalt. Die bauliche und künstlerische Aktivität der Mönche dauerte auch im 17. Jh. fort, als die Fassade des Katholikons und das Beinhaus des Klosters bemalt wurden. Am Ende des Jahrhunderts wurden die meisten Klostergebäude durch einen großen Brand beschädigt. Gegen Anfang des 18. Jhs. wurde das Katholikon wieder aufgebaut und 1732 neu bemalt. In der zweiten Hälfte des 18. Jhs. verlor das Kloster seine Selbstständigkeit und wurde ein Metochion des Klosters Iviron vom Berg Athos, das aber schon im 14. Jh. eigene Stifte in Melnik und seiner Umgebung hatte. Die vollständige Renovierung und künstlerische Konservierung des Klosters wurde Anfang der 80er Jahre unseres Jahrhunderts abgeschlossen. Ein großer Teil der im Kloster aufbewahrten Ikonen und liturgischen Gefäße sind im Klostermuseum ausgestellt ${ }^{1}$.

Die Ikone der Gottesmutter Rhetorissa befindet sich im Klostermuseum (Abb. 1). Sie ist auf ein einziges, in der

der vorliegende Text wesentlich ergänzt und zum Druck vorbereitet. 1. Zur Geschichte und zu Kunstgegenständen des Klosters von Rožen sowie die gesamte Literatur darüber, siehe: G. Gerov, B. Penkova, R. Božinov, Stenopisite na Roženskija manastir, Sofia 1993 (bulg.). 
Mitte leicht vertieftes Stück Holz $(115 \times 74 \mathrm{~cm})$ gemalt. Der Rahmen ist mit schwarzer und roter Farbe gemalt. Die monumentale Halbfigur der Gottesmutter mit Christus auf dem linken Arm erfüllt fast das ganze Bild. Das hellrote Maphorion umfaßt ihre ganze Figur. Auf ihrem Kopf ist eine große, mit Edelsteinen verzierte Krone des sog. «offenen» Typs abgebildet, die wahrscheinlich westlichen Vorbildern folgt. Unter dem Kekriphalos treten die Enden eines roten Schleiers hervor. Auf dem Maphorion ist auf dem Kopf und auf der rechten Schulter je ein rundes Medaillon - ein rotes und ein blaues - mit anthropomorphen Zügen abgebildet. Der Kopf der Gottesmutter ist leicht nach links geneigt, ihr Blick ist über den Kopf des Jesuskindes hinweg auf den Bildbetrachter gerichtet. Christus ist nicht als traditionelles Jesuskind abgebildet, sondern dem Jünglingstyp des Christus Emmanuel nachempfunden. Er sitzt auf dem Arm seiner Mutter fast frontal zum Beschauer gewandt; in der linken Hand hält er eine kleine Schriftrolle, mit der rechten macht er das Segenszeichen. $\mathrm{Er}$ ist in einen taubengrauen Chiton gekleidet, der an Hals, Ärmeln, Taille und Schultern verziert ist. Das feuerrote Himation ist auf seine Knie hinabgeglitten. Während das Jesuskind von der Gottesmutter auf dem linken Arm getragen wird, hält sie in Brusthöhe mehrere Gegenstände in ihrer rechten Hand: eine Steinmauer mit einem Turm. Hinter der Mauer ist eine Abbildung einer Christusbüste zu erkennen, die Christus als Großen Hohenpriester oder König der Könige darstellt. Er trägt ein rotes Gewand und eine Mitra. Ferner sind ein Fels mit einem Baum, eine Leiter und ein rotes Rad zu erkennen. Vor der Brust der Gottesmutter verläuft ein schmaler roter Bogen. Über ihrer rechten Schulter ist auf goldenem Grund mit kleinen roten Buchstaben das Attribut PHTORICA geschrieben. Wie üblich sind die Signaturen von Christus und der Gottesmutter wiedergegeben ${ }^{2}$.

In der beschriebenen Ikone fällt sofort die ungewöhnliche Interpretation der bekannten Gestalt der Gottesmutter Hodigitria auf. Außer einigen Details wie dem dünnen
Schleier, der großen Krone und der Gewandung Christi fallen die Gegenstände, die die Gottesmutter vor der Brust hält, am stärksten auf. In dieser Form kommen sie in den Werken der byzantinischen und postbyzantinischen Kunst des Balkans nicht vor. Tatsächlich wurden in der byzantinischen Kunst schon seit dem 12. Jh. einige von ihnen als Symbole der sog. Präfigurationen der Gottesmutter, als alttestamentliche Prophezeiungen über die Rolle von Maria im Akt der Inkarnation und ihrer unbefleckten Geburt, abgebildet ${ }^{3}$. Die Leiter und der Fels gehören zu den verbreitetsten Symbolen der Gottesmutter. Das Rad, der Bogen und die Festung mit dem Bild Christi dahinter sind in der bildlichen Tradition der Byzantiner nicht anzutreffen.

Nahe Parallelen unserer Ikone sind in der russischen Ikonenmalerei zu finden. Gegen Mitte des 16. Jh. erschienen in der russischen Ikonenmalerei zwei ikonographische Typen, die schnell Verbreitung fanden und bis in die Neuzeit nachgebildet wurden. Diese zwei Typen sind aber nur für die russische Kunst typisch und in Ikonen anderer Länder des christlich-orthodoxen Ostens aus jener Zeit nicht zu finden. Zum einen sind es Ikonen der sog. Gottesmutter «Gora nerukosečnaja» («Nicht von Menschenhänden gespaltener Stein») (Abb. 2), zum anderen Ikonen der Gottesmutter «Neopalimaja kupina» («Unverbrannter Dornbusch») (Abb. 3). Ohne auf die Entstehungsgeschichte und die Herausbildung ihrer Ikonographie näher einzugehen, die noch nicht ausreichend erforscht $\operatorname{sind}^{4}$, soll hier der interessante Versuch von N. P. Kondakov zur Erklärung der eigenartigen ikonographischen Typen erwähnt werden ${ }^{5}$. Nach Kondakov gehört das Thema der Gottesmutter «Gora nerukosečnaja» vollständig zur Ikonographie des Westens. Die Gottesmutter «Neopalimaja kupina» kommt zunächst in Griechenland vor. Von dort wurde sie nach Rußland gebracht. Da die Annahmen von Kondakov nicht durch Beweise untermauert werden und bis jetzt keine ähnlichen Beispiele aus der Kunst Westeuropas oder des Balkans bekannt sind, wird der rein russische Ursprung beider Themen angenommen.
2. Eine Abbildung der Ikone ist bei E. Bakalova, Roženskijat manastir, Sofia 1990 (bulg.) zu finden.

3. Zu den Präfigurationen der Gottesmutter in der byzantinischen Kunst siehe: S. Der Nersessian, «Program of the Frescoes of the Parecclesion. The Kariye Djami, vol. 4", Studies in the Art of the Kariye Djami and its Intellectual Background, Princeton 1975, 303-350; O. Etingof, Ėrmitažnij pamjatnik vizantijskoj živopisi konza 12 veka (Stil' i ikonografija), Vostočnoe Sredisemnomorie i Kavkaz 4-16 vekov.
Sbornik statej Gosudarstvennogo Ėrmitaža, Leningrad 1988, 140-159 (russ.); V. Milanovič, Proroci su te nagovestili, Arhiepiskop Danilo II $i$ njegova doba, Beograd 1991, 409-424 (serb.).

4. V. Vinogradov, «Opyt sravnitel'nogo opisanija nekotorych simvoličeskich ikon drevnerusskogo isskustva», Izvestija Russkogo archeologičeskogo obščestva, IX, vyp. I, St. Petersburg 1877, 1-43 (russ.).

5. N. Kondakov, Russkaja ikona, IV, Cast'vtoraja, Praga 1933, 288, 290 (russ.). 


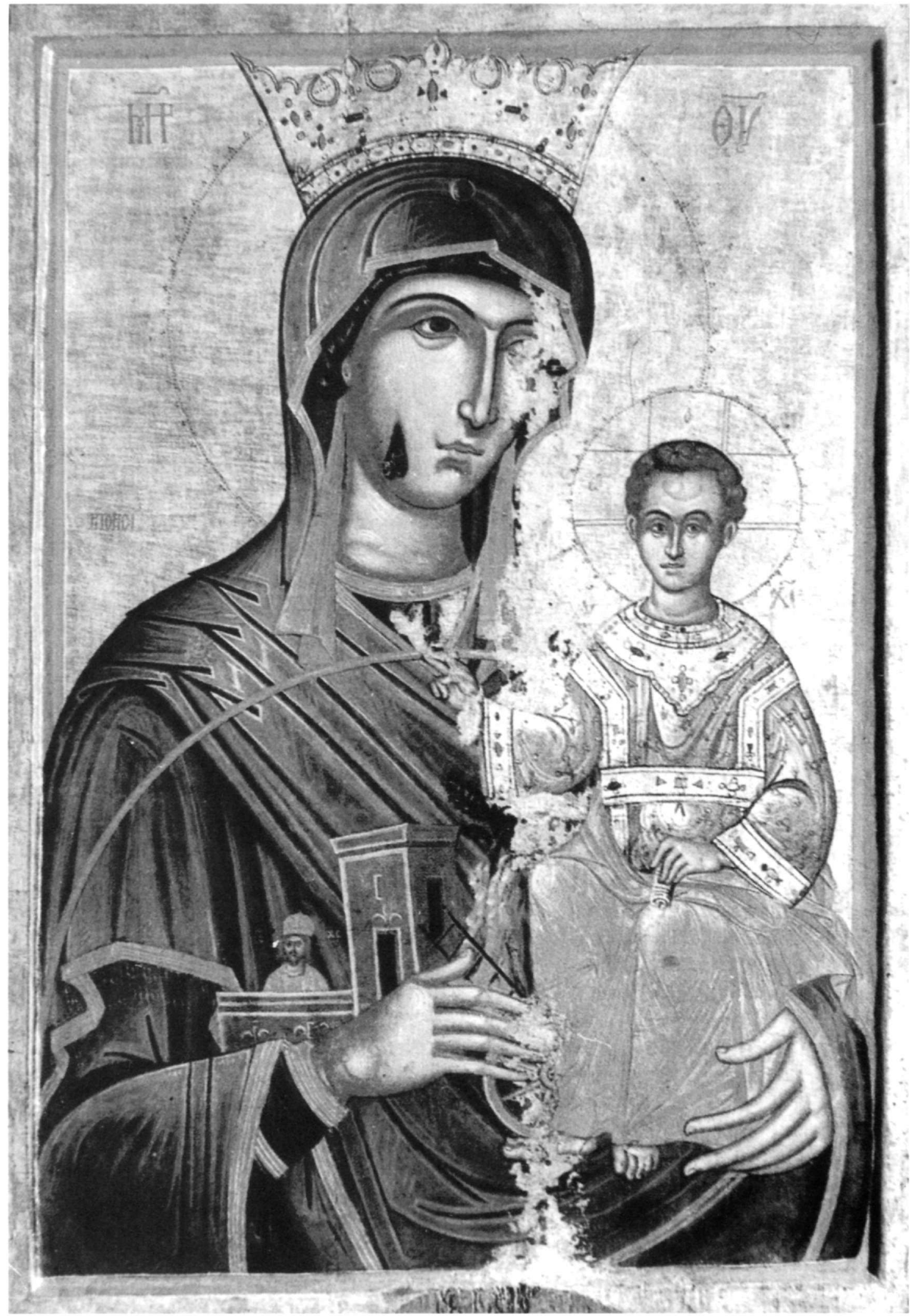

Abb. 1. Die Ikone der Gottesmutter Rhetorissa aus dem Rožen-Kloster in der Nähe von Melnin. 


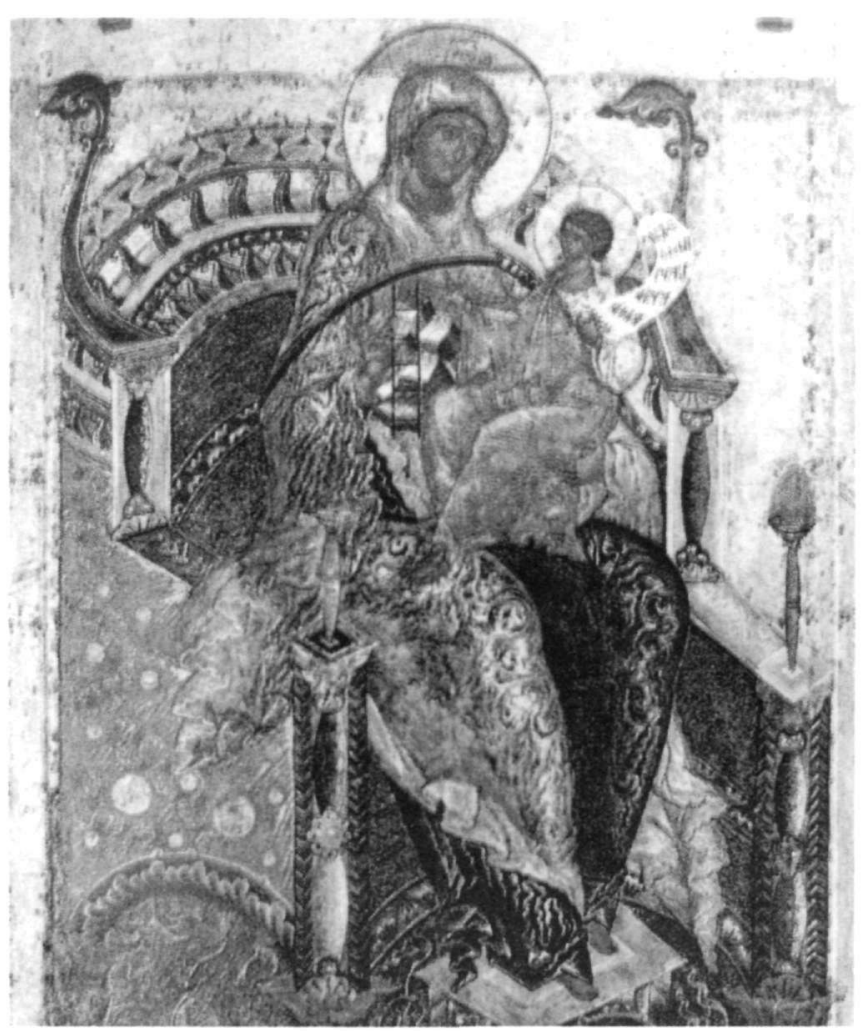

Abb. 2. Die Gottesmutter «Gora nerukosečnaja».

Die Ikonen der Gottesmutter «Gora nerukosečnaja» stellen die Gottesmutter thronend mit dem Jesuskind auf dem linken Arm dar (Abb. 2-3). In der rechten Hand hält sie einen Fels, eine Leiter und einen schmalen Bogen, der vor ihrer Brust verläuft. Ihr Maphorion ist wie aus Wolken gewoben, und auf dem Kopf und an der rechten Schulter sind kleine Medaillons abgebildet, die menschliche Gesichter einfassen, aus deren Mündern Strahlen austreten. Wie die Bezeichnung zeigt, wurden diese Ikonen durch die Episode vom ersten Traum Nabukadnezars und dessen Deutung durch den Propheten Daniel (Dan. 2, 34-35) inspiriert. In seinem Traum sah der König einen Stein, der von einem Berg herunterkam und ohne das Zutun von Menschenhänden das schreckliche Bild zermalmte. Der Stein selbst wurde zu einem großen Berg, der die ganze Welt erfüllte.

Traditionell wird diese Episode als Prophezeiung der ewigen Jungfräulichkeit der Gottesmutter gedeutet. Sie ist

6. V. Antonova, N. Mneva, Katalog drevnerusskoj živopisi, Moskva 1963, I, 364, Kat. Nr. 312 (russ.).

7. L. Kologrivova, O solovečkom sobranii ikon. Architekturno-hudožest- der Berg, und Christus ist der Stein, der ohne Zutun von Menschenhänden vom Berg herunterkam, die heidnischen Götzen zerstörte und als neuer Glaube die ganze Welt erfüllte. Unter den bekannten veröffentlichen Ikonen der Gottesmutter «Gora nerukosečnaja» ist die aus der Sammlung der Tretjakov Galerie vielleicht die früheste. Sie wird in das 15 . Jh. datiert ${ }^{6}$. Die früheste datierte Ikone befindet sich im Museum in Kolomenskoe in Moskau. Sie stammt aus der Ikonostase der Verklärungskirche des Solovetzki-Klosters und wird in die Zeit zwischen 1558 und 1566 datiert $^{7}$.

Die Ikonen mit dem Bild der Gottesmutter «Neopalimaja kupina» (Abb. 4) weisen eine wesentlich kompliziertere Ikonographie als die der Gottesmutter "Gora nerukosečnaja» auf. Die Gottesmutter mit dem Jesuskind wird vor dem Hintergrund eines kompliziert aufgebauten Scheins, gebildet durch die Überschneidung von zwei Rhomben, einem grünen und einem roten, dargestellt. In den dreieckigen Bereichen, die durch die Überschneidung der Rhomben entstehen, sind eine Vielzahl von Himmelskräften und die Symbole der Evangelisten abgebildet. Außer dem Jesuskind, das gewöhnlich in sehr bewegter Körperstellung abgebildet wird, hält die Gottesmutter einen Fels mit einer Festung in der Hand. In der Festung ist Christus mit einer Krone dargestellt. In den Ecken der Ikone werden kleine Szenen gezeigt, die die bekanntesten Präfigurationen der Gottesmutter darstellen: Moses vor dem brennenden Dornbusch, die Wurzel Jesse, Hesekiel vor den geschlossenen Toren und Jakobus mit der Himmelsleiter. Der grüne Rhombus hinter der Gottesmutter wird als Dornbusch, der rote als Feuer gedeutet. Die Gruppe der Engel und weiteren Himmelskräfte symbolisieren den Wind, die Kälte, den Sturm u.a. Naturelemente. Die Bezeichnung dieses Ikonentyps verweist auf das Alte Testament, auf die Vision Moses vor dem brennenden Dornbusch, der nicht durch das Feuer verzehrt wird (Exodus 3, 2-4). Ihrem Wesen nach eine Theophanie, bildet diese Vision eine der beliebtesten Prophezeiungen zur unbefleckten Empfängnis der Gottesmutter. Was die Symbolik der Ikonen mit der Gottesmutter «Neopalimaja kupina» betrifft, vereint sie nach der gelungenen Definition von L. Vorontzov sehr geschickt die Apotheose der Allheiligen Jungfrau einerseits und die kosmogonischen Vorstellungen der Slawen andererseits, in denen Überlieferungen aus ihrem heidnischen Glauben vorkamen ${ }^{8}$. Die Ikonen der Gottes-

vennye pamjatniki Soloveckich ostrovov, Moskva 1980, 208 (russ.). 8. V. Vorontzov, «Neopalimaja kupina», Žurnal Ministerstva Narodnogo Prosvjashtenija, Bd. 352, Mart 1904, 62-88 (russ.). 


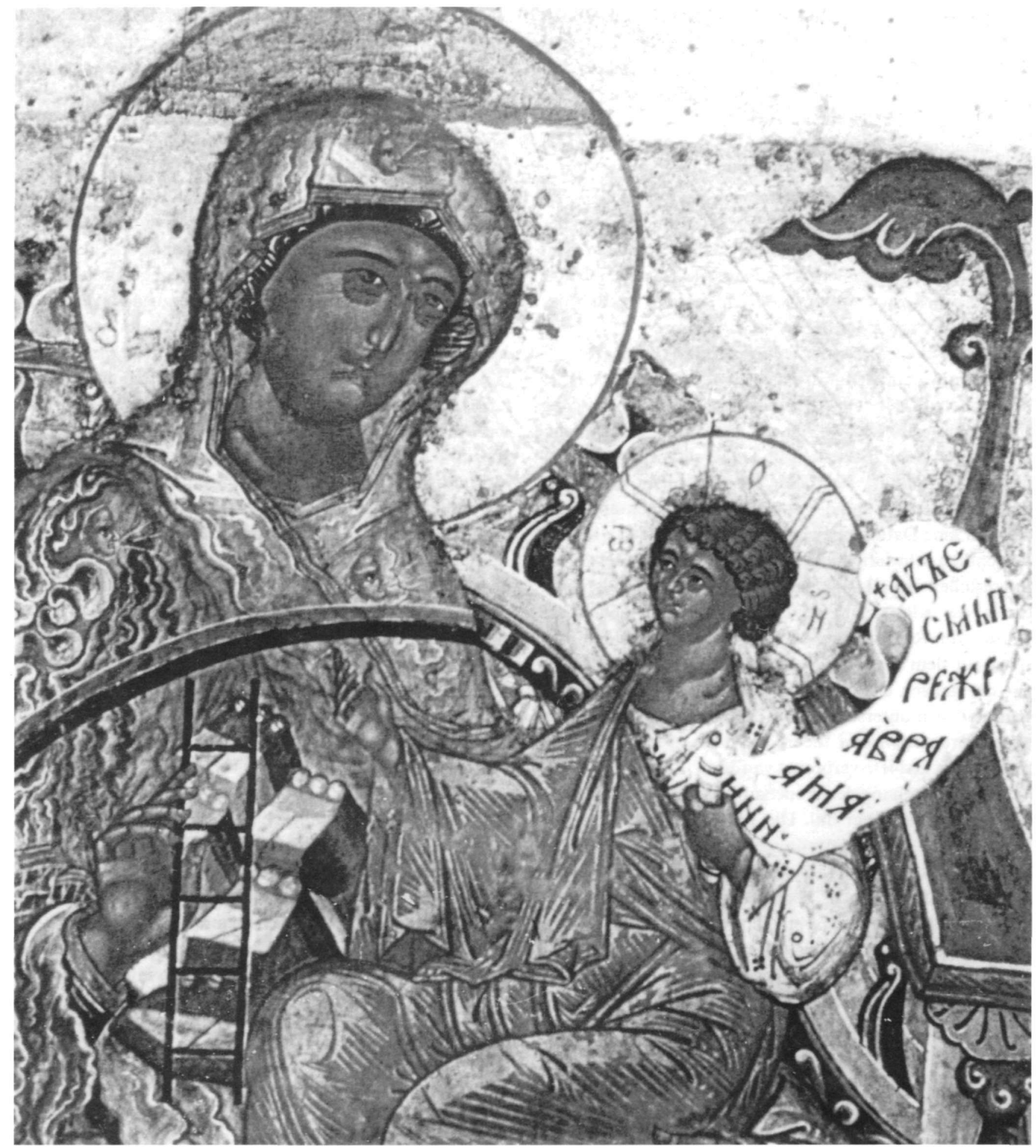


mutter «Neopalimaja kupina» sind zahlreicher als die Ikonen vom Typ der Gottesmutter «Gora nerukosečnaja» ${ }^{9}$. Sie sind in der russischen Ikonenmalerei gegen Mitte des 16. Jh. entstanden und wurden von dieser Zeit an verbreitet.

Der Vergleich der Ikone von Rožen (Abb. 1) mit den beiden genannten Ikonentypen zeigt Ähnlichkeiten in bezug auf die Gegenstände, die die Gottesmutter hält, sowie weitere Details. Wiederholt kommen die Leiter, der Fels und die Mauer mit Christus vor. Doch das rote Rad aus der Ikone vom Rožen-Kloster ist in den russischen Ikonen nicht zu finden. Es wiederholen sich auch die kleinen Medaillons mit Menschengesichtern am Kopf und an der Schulter der Gottesmutter sowie der Bogen vor ihrer Brust.

Die stilistischen Besonderheiten der Ikone des RoženKlosters sind ein Zeugnis dafür, daß sie das Werk eines Zographen ist, der zunächst einmal der postbyzantinischen Tradition angehörte. Die Art der Gestaltung der Gesichter, eine gewisse Trockenheit und eine ausgesprochen graphische Darstellung der Falten des Gewandes, die Stärke der Holzunterlage und der eher schmale Ikonenrand sprechen für eine Datierung der Ikone an das Ende des 17. Jhs. Wesentlich schwieriger ist der Entstehungsort der Ikone festzustellen. Höchstwahrscheinlich stammt sie eher von einem der Klöster auf dem Berg Athos, zu denen das Kloster von Rožen enge Beziehungen pflegte. In den Klöstern auf dem Heiligen Berg Athos wurden Kunstwerke aus der ganzen christlichen Welt gesammelt. Dort überschnitten sich unterschiedliche Einflüsse, von dort kamen neue Anregungen und Ideen, die dann in alle christlichorthodoxen Gebiete verbreitet wurden.

Von der Entstehung der Ikone auf dem Balkan zeugt nicht nur ihr künstlerischer Stil. Die Ideengrundlage für diese Ikone wurzelt in der byzantinischen Tradition der bildlichen Darstellung der Präfigurationen der Gottesmutter. Offensichtlich ist sie das Werk eines außerordentlich gebildeten Malers, der nicht nur ihr «Ideenprogramm» darstellte, sondern auch nach neuen, für die byzantinische künstlerische Praxis nicht üblichen Ausdrucksmitteln gesucht hat. Die wahrscheinlichste Quelle des Ideenprogramms der Ikone stellt die byzantinische Hymnographie,

9. V. Antonova, N. Mneva, op. cit. I, 52; II, 30, 207, 348.

10. Im Altslawischen bedeutet das dafür benutzte Wort «krasno» nicht nur «(wunder)schön» sondern auch «hellrot». Vielleicht ist es kein $\mathrm{Zu}$ fall, daß in der Farbpalette der Ikone von Rožen das Hellrot vorherrscht. 11. E. Bakalova, «Aspekti na saotnoschenieto 'tekst-isobrazenie' v balgarskota zivopis», Problemi na iskustvoto I (1991), 9-10 (bulg.). insbesondere der Akathistos der Gottesmutter, dar. Der Text der 17. Strophe (9. Oikos) zielt darauf hin, das in Worten zu fassende Mysterium der Menschwerdung des Logos und der jungfräulichen Empfängnis Maria zu beschreiben. Die Strophe beginnt mit den Worten «PH-

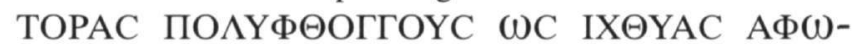
NOYC OPWMEN EПI COI @EOTOKE...». Es scheint, $\mathrm{da} ß$ das originelle Attribut der Gottesmutter in der Ikone von Rožen PHTOPICA aus diesem Hymnus übernommen wurde. Im Sinne der Symbolik der Ikone ließe sich dieses Attribut nicht nur von «Rhetor» abgeleitet deuten, sondern auch als ein Attribut, das sich auf das Wesen der Gottesmutter selbst bezieht. Sie ist auch «redegewandt», weil sie das echte «wohlklingende» Wort in sich trägt ${ }^{10}$, sie läßt die wortgewandten Rhetoren verstummen und entlarvt die falschen Weisen. Zu Recht nimmt E. Bakalova die Ikone von Rožen in den Prozeß der visuellen « Umsetzung» der von Allegorien und Symbolen erfüllten byzantinischen Dichtung für die Gottesmutter auf ${ }^{11}$. Eben in der abschließenden Phase dieses Prozesses wurde eine derartige Übernahme von Ausdrucksmitteln von einem anderen Darstellungssystem (der russischen Ikonenmalerei jener Zeit) anstelle einer Entwicklung einer originellen Darstellung möglich, die für die klassische byzantinische Periode charakteristisch war.

Das originelle Attribut der Gottesmutter der Ikone vom Rožen-Kloster lenkt die Aufmerksamkeit auf die Figur des Rhetors und auf seine Position in der byzantinischen und postbyzantinischen Gesellschaft. Die byzantinische Ausbildung hatte zahlreiche Lehrfächer vom spätantiken Bildungssystem übernommen, darunter auch die Kunst der Rhetorik $^{12}$. An der Höheren Schule des Patriarchats in Konstantinopel war für die Rhetorik und Philosophie der sog. «Meister der Rhetoren» zuständig, der im 11.-12. Jh. der dritten Pentade OФФIKIA THC MEГA $\Lambda$ HC EKK $\Lambda$ HCIAC angehörte ${ }^{13}$. Nach der Restauration des Reiches 1261 lautete sein Titel «Rhetor der Rhetoren» ${ }^{14}$. Der Rhetor behielt sein hohes Amt in der kirchlichen Hierarchie auch nach der Eroberung des Byzantinischen Reiches durch die Türken. Ein synodales Dokument, ausgestellt durch den

12. $O D B$, New York - Oxford 1991, Bd. 3, 1788 (Rhetoric).

13. J. Darrouzès, Recherches sur les OФФIKIA de l'église byzantine, Paris 1970.

14. F. Fuchs, Die Höheren Schulen von Konstantinopel im Mittelalter, Leipzig-Berlin 1926, 40, 57. 
DIE IKONE DER GOTTESMUTTER RHETORISSA IM KLOSTER ROŽEN

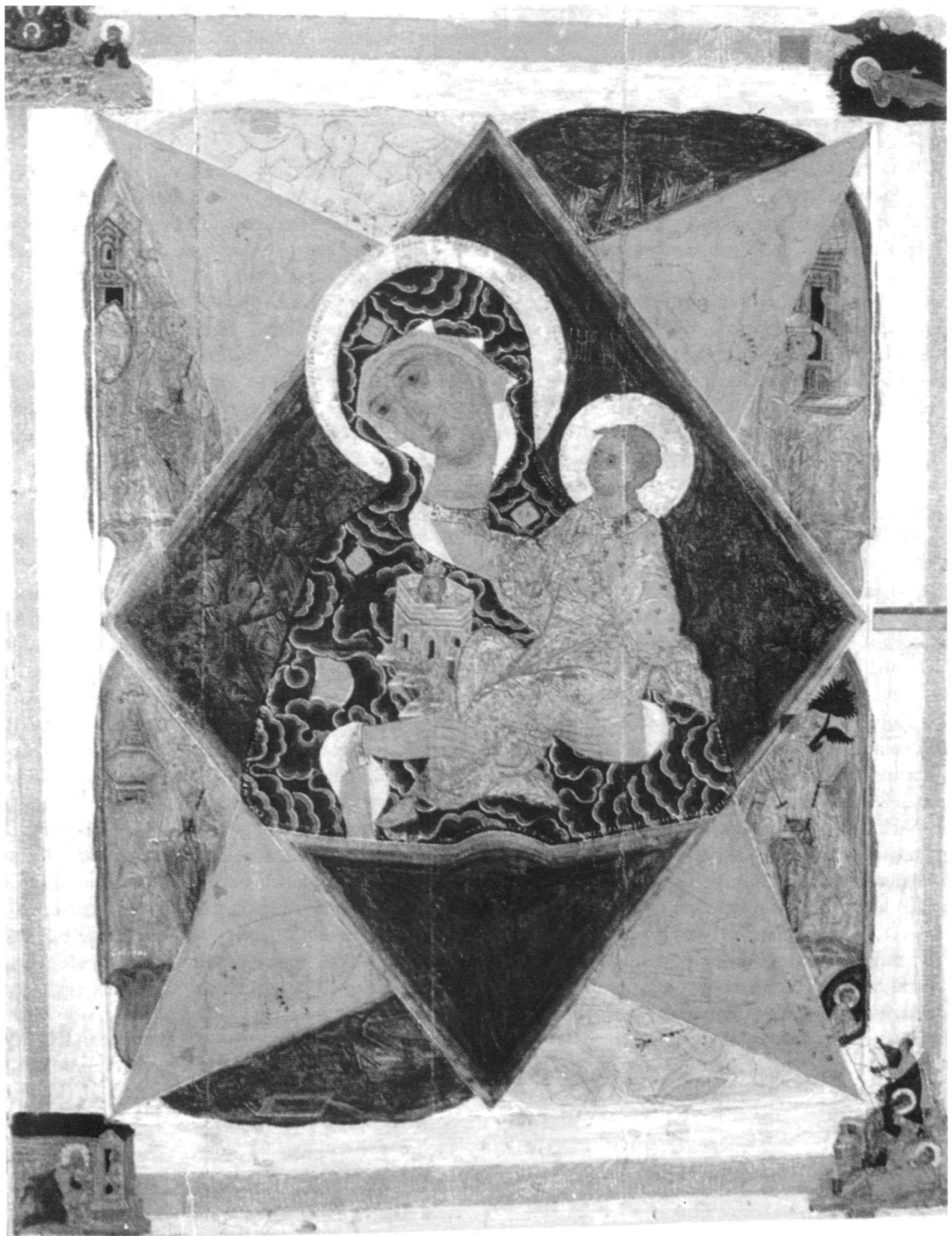

Abb. 4. Die Gottesmutter «Neopalimaja kupina». 
Patriarchen von Konstantinopel Jeremias II. Tranos am Ende des 16. Jhs. zeigt, daß der Rhetor zu den fünf Ranghöchsten in der Hierarchie des Partiarchats von Konstantinopel gehörte (seinem Rang nach folgte er unmittelbar dem großen Chartophylax) und für die kirchliche Ausbildung der Gläubigen zuständig war ${ }^{15}$. Die Schule des Patriarchats in Konstantinopel war im Laufe der Jahrhunderte in unterschiedlichen Kirchengebäuden der byzantinischen Hauptstadt untergebracht: in der Kirchenanlage der Hagia Sophia, in der Hl. Apostel-Kirche sowie in der Kirche der Gottesmutter Diakonissa ${ }^{16}$. Man könnte dies als einen indirekten Hinweis auf die Verehrung der Gottesmutter als Beschützerin der im Bildungsbereich beschäftigten Mitglieder des hohen Klerus in Byzanz ansehen.

Im Jahre 1710 schrieb der russische Mönch Kosmas seine "Rhetorik», die teilweise eine Übersetzung des in Venedig in griechischer Sprache erschienenen Buches von Francesco Scuffi «Die Kunst der Rhetorik» war ${ }^{17}$. Im Vorwort zu seinem Werk erklärte der Mönch Kosmas, daß er dieses Werk der Gottesmutter als Beschützerin der Rhetoren widme. In der Widmung, die von den Forschern als Übersetzung aus dem Griechischen angenommen wird, heißt es u.a.: «зане самая сущи источник мудрости, естествено риторстовала еси... $O$ пречюgныя риторики, о всемогущаго ритора, о неизреченныя силы твоея, богороgительниие, неизглаголаннаго твоего риторства крепости. Тебе убо, о мудра госпоже моя, приноиу сию книгу...» ${ }^{18}$, oder: «Weil Du selbst eine echte Quelle der Weisheit bist, hast Du Deinem natürlichen Wesen nach als Rhetorin gehandelt... O wundervolle Rhetorik, o allmächtiger Rhetor, wie aussprechlich Deine Macht, Gottesgebärerin, eine Festung Deiner unsagbaren Rhetorikkunst. Dir o meine weise Herrin, bringe ich dieses Buch...». Obwohl keine weiteren Nachweise über die Verehrung der Gottesmutter als Beschützerin der Rhetoren in der byzantinischen Zeit vorliegen, zeigt das angeführte Zitat, daß eine solche Tradition in späteren Zeiten existiert hat.

Einige Details der Ikone des Rožen-Klosters ergänzen die Analyse dieses Denkmals. Im Bild der Gottesmutter fallen die große prächtige Krone und die Enden des roten
Schleiers auf, die unter dem Maphorion hervortreten. Die byzantinische Ikonographie kennt das Bild der Gottesmutter als Königin nur aus der Deesis-Komposition als Illustration zum Psalm 45, in der russischen Tradition auch als «Predsta Zariza» bekannt. Gleichzeitig waren die Abbildungen von Maria mit Krone in der westlichen Kunst des Mittelalters schon seit frühesten Zeiten außerordentlich verbreitet. Unter deren Einfluß wurde dieses Detail in die postbyzantinische Malerei des Balkans übernommen und für die Ikonenmalerei des 18. Jhs. kennzeichend. Doch auch in dieser Zeit war der Schleier eine fremde Komponente der Ikonen und Fresken des Balkans, so daß sein Vorkommen in der Ikone von Rožen durch einen direkten Kontakt des Zographs mit den Werken der westlichen Kunst zu erklären ist. Das Gewand Christi unterscheidet sich ebenfalls sehr vom üblichen byzantinischen Chiton. Obwohl keine direkten Parallelen dieses Gewandes gefunden wurden, müssen die Modelle wahrscheinlich in der zeigenössischen russischen Malerei zu suchen sein.

Die Ikone der Gottesmutter Rhetorissa aus dem RoženKloster ist ein einmaliges Werk der postbyzantinischen Malerei des Balkans, das die typischen Besonderheiten des künstlerischen Denkens der Epoche zwischen dem Mittelalter und der Neuzeit widerspiegelt. Das alte byzantinische Bildsystem hatte seine Möglichkeiten weitgehend ausgeschöpft und die gebildeten Zographen suchten nach neuen Darstellungsweisen. Der Meister, der die Ikone von Rožen gemalt hat, vereinte mehrere verschiedenartige Komponenten zu einem harmonischen Ganzen: die traditionelle byzantinische Darstellungsweise mit einer typisch russischen Ikonographie und typisch westlichen Details. Dieser Eklektizismus ist ein Phänomen, welches die Kunst der späten postbyzantinischen Phase der balkanischen Kunst im allgemeinen kennzeichnet. Er ist vielleicht auch die Ursache dafür, daß die Ikone von Rožen eine isolierte Erscheinung blieb, ohne Parallele unter ihren zeigenössischen Malereidenkmälern, als Kunstwerk einer Epoche, die im Zeichen eines tiefgreifenden, schicksalhaften Wandels stand, welcher das jahrhundertealte Bildsystem der byzantinischen Kunst praktisch zerstören sollte.

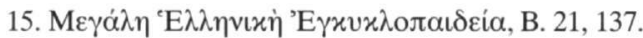

16. R. Browning, The Patriarcal School at Constantinople in the Twelfth Century. Studies on Byzantine History, Literature and Education, Variorum Reprints, London 1977, X, 174.
17. N. Ponurko, Bogorodica - pokrovitel'nica ritorov. Russkaja i gruzinskaja srednevekovye literatury, Leningrad 1979, 200-203 (russ.). 18. Ibid., 200. 